\title{
Comparative Study between 12 and 15 Lead Electrocardiograms for Evaluation of Acute Posterior Myocardial Infarction
}

\author{
SMA Wahab ${ }^{1}$, AEMM Islam ${ }^{2}$, MM Haque ${ }^{3}$, SMD Hossain ${ }^{1}$, MM Kamal $^{1}$, SY Ali $^{2}$, SMEE Mahabub ${ }^{4}$ \\ ${ }^{1}$ Department of Cardiology, Khulna Medical College, ${ }^{2}$ Department of Cardiology, Faridpur medical \\ College, ${ }^{3}$ Department of Cardiology, Shaihd Sheikh Abu Naser Specialized Hospital, Khulna, \\ ${ }^{4}$ Department of Cardiology, Dhaka Medical College Hospital.
}

\begin{abstract}
:
Background: The ECG diagnosis of acute posterior infarction has traditionally been based on the presence of ST segment depression on the pericardial chest leads. However, such ST segment depression is neither specific nor sensitive for the diagnosis of a posterior infarction. Detection of ST segment elevation in V7- V9 in 15 lead ECG can help in early diagnosis of acute Posterior myocardial infarction.

Method: Total of 100 patients Inferior myocardial infarction was evaluated by Electrocardiography in standard 12 lead and 15 lead. The patients were categorized into group I having posterior/ and or associated changes and group II having without posterior changes in ECG. Echocardiography and LVgraphy was done to evaluate the posterior wall movement.

Result: For diagnosis of posterior myocardial infarction, $43.3 \%$ sensitivity and $95.1 \%$ specificity was found in 12 lead ECG, whereas in 15 lead ECG it was $80.0 \%$ sensitivity and $95.1 \%$ specificity.

Conclusion: 15 Lead ECGs (including V7-V9) more sensitive than 12 lead ECGs in diagnosis of acute posterior myocardial infarction. Patient with inferior myocardial infarction or anterior ischemia developed more complications if associated with acute posterior myocardial infarction. 15 lead ECGs can routinely be used in patients with ischaemic type of chest pain.
\end{abstract}

(Cardiovasc. j. 2012; 4(2): 153-163)

\section{Introduction:}

Ischaemic heart disease is a major health problem throughout the world. In the western countries 50\% of all death are due to cardiovascular diseases, half of these are attributed to myocardial infarction. ${ }^{1}$ In Bangladesh coronary artery disease is the third largest cause of death today. One survey by Malik et $\mathrm{al}^{2}$ detected the prevalence rate of IHD as 3.3/ thousand and a multicentre study by Farid $\mathrm{N}$ et al ${ }^{3}$ revealed prevalence of IHD as 14/thousand .

The diagnosis of acute myocardial infarction requires a joint evaluation of the clinical aspects, the ECG and the serum enzyme activity. ST Segment of the electrocardiogram (elevation in the leads overlying the infarction and depression in the reciprocal leads) is altered very early in the course of AMI and is one of the indirect markers of myocardial damage. Latter on pathological $\mathrm{Q}$ wave and $\mathrm{T}$ wave inversion occur. But in many instances, it (about $50 \%$ of patients with AMI) does not show diagnostic ECG changes. ${ }^{4}$

Moreover the standard 12 lead ECG is a relatively insensitive tool for detecting posterior myocardial infarction. ${ }^{5}$ This a particularly true in the acute stage when prompt and accurate diagnosis of AMI is critical in determining the initiation of reperfusion therapy. ${ }^{6}$ The major obstacle in the ECG diagnosis of posterior myocardial infarction lies in the absence of standard leads facing the posterior left ventricular wall, which results in failure to reveal ST segment elevation in a high proportion of patients with acute posterior infarction. Recently it was demonstrated that during acute inferior infarction, ST segment elevation in the posterior chest leads V7-V9 identifies those patients with concomitant posterior wall involvement. ${ }^{7}$ It was shown that ST segment elevation is present solely in posterior chest leads in $3 \%-4 \%$ of all patients with AMI and in as many as $20 \%$ of Ami patients without ST segment elevation on the standard 12 lead. ${ }^{8}$

Shlomi M et al ${ }^{8}$ showed that in acute posterior myocardial infarction ST segment elevation was present in lead V7 and V9 in 91\% and in lead V8 in $100 \%$ patients. Prominent R-wave appeared in lead V1 in $9 \%$ and in lead V2 in $44 \%$. In $25 \%$ patients, on admission, no pathologic ST segment changes were noted in standard 12 lead ECG and the ST segment elevation in leads V7 through V9 was the only pathologic ST segment change. 
The ECG diagnosis of acute posterior infarction has traditionally been based on the presence of ST segment depression on the pericardial chest leads. ${ }^{9,10}$ However, such ST segment depression are neither specific nor sensitive for the diagnosis of a posterior infarction. These ECG change might be caused by at. Ischaemia ${ }^{11}$ and therefore do not constitute an indication for thrombolytic therapy (TIMI-III B. Investigation 1994). Prominent $R$ wave in V1-V2, which might be a manifestation of posterior myocardial infarction, do not enable the determination of the age of the infarction. Shlomi M demonstrates that Isolated with acute posterior myocardial infarction and moderate to severe MR were detected in $22 \%$ of such cases. ${ }^{8}$ Thus ST segment elevation in leads V7-V9 identify infarctions that are potentially harmful, out of proportion to their size owing to their special location in the left ventricle and thereby their potential to cause MR. The presence of mitral regurgitation after acute myocardial infarction is associated with the development of hemodynamic deterioration of heart failure and poor prognostic outcome.

The presence of ST segment elevation in leads V7V9 may contribute to the triage of patients with chest pain and help in the early differentiation between patients with acute posterior myocardial infarction and those with anterior wall ischemia. This distinction may influence the decision making process regarding the treatment of patients with acute coronary syndrome. Currently, the indication for thrombolytic therapy requires the presence of ST segment elevation in the standard 12-lead ECG. However, because ST segment elevation is not seen on the standard 12 lead ECG in up to $50 \%$ of patients with posterior or circumflex-related infarction ${ }^{12,6}$ the presence of ST should be sought in leads V7-V9. This sub-group of AMI patients can be benefited from thrombolysis or PTCA. Thrombolytic therapy in MI also reduces the incidence of significant MR.

\section{Objectives-}

1. To find out the utility of doing V7-V9 chest leads in addition to conventional 12 lead electrocardiogram in patients with ischemic type of chest plain.

2. To evaluate the degree of association of posterior wall myocardial infarction with other wall infarction or ischemia.

3. To find out in-hospital outcome of patients with acute posterior myocardial infarction with or without other wall infarction.

\section{Material \& methods}

This prospective study was performed on 100 selective patients admitted in the Department of Cardiology, NICVD, Dhaka on the basis of inclusion and exclusion criteria. during the period from July 2000 to December 2000

\section{Inclusion criteria}

Selected patients presenting with acute inferior myocardial infarction for the first time or anterior ischemia having.

A. Typical ischemic chest pain for more than 30 minutes with onset within preceding 24 hours.

B. ECG: ST segment elevation or depression contiguous e"2 leads in conventional 12 lead ECG with or without ST elevation in V7-V9.

\section{Exclusion Criteria}

a. Chest Pain persisting for less than 30 minutes or onset is more than 24 hours.

b. Patients who was got Streptokinase for this episode of myocardial infarction.

c. History and evidence of previous myocardial infarction.

d. Patient with anterior myocardial infarction or right ventricular infarction.

e. Pericarditis, Myocarditis, Cardiomyoparthy.

f. Patients with RBBB, RVH, LBBB, cardiac pacing.

g. Significant Valvular and Congenital heart diseases.

\section{Electrocardiographic evaluation (ECG)}

A standard 12 lead ECG were performed in all patients on admission and within 24 hours of admission. During arrhythmia or chest pain, repeat ECG was done. The Magnitude of ST-segment deviation was measured from the baseline (TPsegment). Significant ST-depression was defined as $1 \mathrm{~mm}$ or greater horizontal or down-sloping STdepression measured at $20 \mathrm{~ms}$ after the J point. The ECG reports were carefully analyzed and the serial ECGs were compared to detect any complication like extension of infarction, pericarditis, arrhythmia, etc. In case of inferior AMI, right pericardial (V4R), leads were recorded on admission or within 2-3 hours of admission. Posterior myocardial infarction was diagnosed if a tall R-wave appeared in lead V1-2 with upright T-wave having R/S ration e"1.0. Particular attention was given to detect any "reciprocal change" in admission-ECG and predischarge-ECG.

\section{Lead ECG}

Patients having chest and back pain in addition to conventional 12 lead ECG, V7-V9 lead ECG was 
done at admission, eight hours after and before discharge. Leads V7 through V9 was recorded on the same horizontal plane as lead V6 and in the posterior axillary line (lead V7), beneath the Scapular angle (V8) and on the paravertiral line (V9) respectively. Significant ST elevation of at least $0.5 \mathrm{~mm}$ in two or more consecutive leads, based on the increased distance between the posterior chest wall and the heart and Q wave wider than $0.04 \mathrm{sec}$ or deeper than one-quarter of amplitude of the succeeding $\mathrm{R}$-wave in two or more consecutive leads was considered pathologic in leads V7 through V9.

\section{Grouping of the patients}

Patients were categorized into Group I and Group II on the basis of 15 lead ECG.

Group I : Patients with acute posterior myocardial infarction (APMI) in 15 lead ECGs $(n=34)$

Group II : Patients without AMPI in 15 lead ECGs $(\mathrm{n}=66)$

Patients of these two groups were followed up during hospital stay. They were monitored through clinical examination (recurrent chest pain, heart failure, mitral regurgitation etc), ECG (arrhythmia or conduction disturbances), cardiac enzymes assay (CK-MB), echocardiogram, left ventriculography (wall motion abnormalities, ejection fraction and development of MR) and coronary angiogram (vessel involvement).

\section{Statistical analysis}

The collected data were checked and coded manually and then entered into computer. The numerical data obtained from the study were analyzed and significance of difference were estimated by using the statistical methods. Data were expressed in frequency, percentage, mean and standard deviation as applicable. Comparison between groups was done by standard ' $t$ ' test, chisquare test, and fisher's exact test as applicable. The sensitivity and specificity of 12 lead and 15 lead ECGs were calculated by comparing with echocardiography and left ventriculography. Data were analyzed but using computer based SPSS program. Probability less than 0.55 were considered as significant.

\section{Results:}

Total of 100 patients were evaluated by Electrocardiography in standard 12 lead and 15

Table-I

Clinical presentation of the study patients

\begin{tabular}{lcccc}
\hline Characteristics & $\begin{array}{c}\text { Group-1 } \\
(\mathrm{n}=34)\end{array}$ & $\begin{array}{c}\text { Group-II } \\
(\mathrm{n}=66)\end{array}$ & $\begin{array}{c}\text { Total } \\
(\mathrm{N}=100)\end{array}$ & $\begin{array}{c}\mathrm{p} \text { value } \\
\text { Back pain }\end{array}$ \\
\hline Dyspnoea & $15(44.1)$ & $4(6.1)$ & $19(19.0)$ & $0.001^{\mathrm{S}}$ \\
Sweating & $19(55.9)$ & $17(25.8)$ & $36(36.0)$ & $0.003^{\mathrm{S}}$ \\
\hline
\end{tabular}

N.B. Figure in parenthesis indicate percentages $p$ value reached from chi-square analysis

Table-II

Risk factors of the study population

\begin{tabular}{|c|c|c|c|c|}
\hline Risk factors & $\begin{array}{l}\text { Group-I } \\
(n=34)\end{array}$ & $\begin{array}{c}\text { Group-II } \\
(\mathrm{n}=66)\end{array}$ & $\begin{array}{c}\text { Total } \\
(\mathrm{N}=100)\end{array}$ & $\mathrm{p}$ value \\
\hline Smoking habit & $18(52.9)$ & $37(56.1)$ & $55(55.0)$ & $0.766^{\mathrm{NS}}$ \\
\hline Hypertension & $10(29.4)$ & $22(33.3)$ & $32(32.0)$ & $0.690 \mathrm{NS}$ \\
\hline Dyslipidaemia & $10(29.4)$ & $10(15.2)$ & $20(20.0)$ & $0.091 \mathrm{NS}$ \\
\hline Family H/O IHD & $8(23.5)$ & $13(19.7)$ & $21(21.0)$ & $0.656^{\mathrm{NS}}$ \\
\hline *Composite risk factors & $1.6 \pm 1.0$ & $1.4 \pm 1.0$ & $1.5 \pm 1.0$ & $0.526^{\mathrm{NS}}$ \\
\hline
\end{tabular}

N.B. Figure in parenthesis indicate percentages

$\mathrm{P}$ value reached from chi-square analysis

*p value reached from unpaired student's test 
Table III

Electrocardiographic diagnosis made by 12 and 15 lead of the study population

\begin{tabular}{lccc}
\hline ECG findings & 12-Lead & 15 -Lead & Final diagnosis \\
\hline Inferior MI with anterior ischemia & $33(33.0)$ & $26(26.0)$ & $26(26.0)$ \\
Anterior ischemia & $31(31.0)$ & $25(25.0)$ & $25(25.0)$ \\
Posterior MI and inferior MI with anterior ischemia & $10(10.0)$ & $16(16.0)$ & $16(16.0)$ \\
Inferior myocardial infarction & $15(15.0)$ & $15(15.0)$ & $15(15.0) q$ \\
Posterior MI with anterior ischemia & $9(9.0)$ & $15(15.0)$ & $15(15.0)$ \\
Posterior MI with inferior MI & $2(2.0)$ & $3(3.0)$ & $3(3.0)$ \\
\hline
\end{tabular}

lead. The patients were categorized into group I having posterior/ and or associated changes in other electrocardiographic lead and group II having without posterior changes in ECG. The mean $( \pm \mathrm{SD})$ age of the patients was $51.9 \pm 9$.0 years. The mean age $( \pm \mathrm{SD})$ for group I was $53.7 \pm 7.4$ and for group II was $50.9 \pm 9.6$ years. It was evident that $87.0 \%$ were male and $13.0 \%$ were female.

Table-I shows the clinical characteristics of the patients. It was found that cent percent had complaints of chest pain followed by sweating (70.0\%), dyspnoea (36.0\%) and back pain (19.0\%).

Table-II Shows the selected risk factors associated with cardiovascular disease. The composite mean
$( \pm \mathrm{SD})$ was $1.5( \pm 1.0)$. Out of 100 patients $55.0 \%$ were smoker followed by hypertension (32.0\%), family history of ischemic heart disease (21.0\%), dyslipidaemia (20.0\%) and diabetes mellitus (19.0).

Table-III shows the electrocardiography diagnosis made by 12 and 15 lead. In 12 lead, highest percentages were IMI with anterior ischemia (33.0\%) followed by anterior ischemia only (31.0\%), IMI (15.0\%), IMI, PMI with anterior ischemia (10.0\%), PMI with anterior ischemia (9.0\%) and IMI and PMI (2.0\%). Similar pattern of ECG findings were found in 15 lead, where $26.0 \%$ was IMI with anterior ischemia followed by anterior ischemia only (25.0\%), IMI and PMI with anterior ischemia (16.0\%), IMI (15.0\%), PMI with anterior ischemia and PMI with IMI (3.0\%)

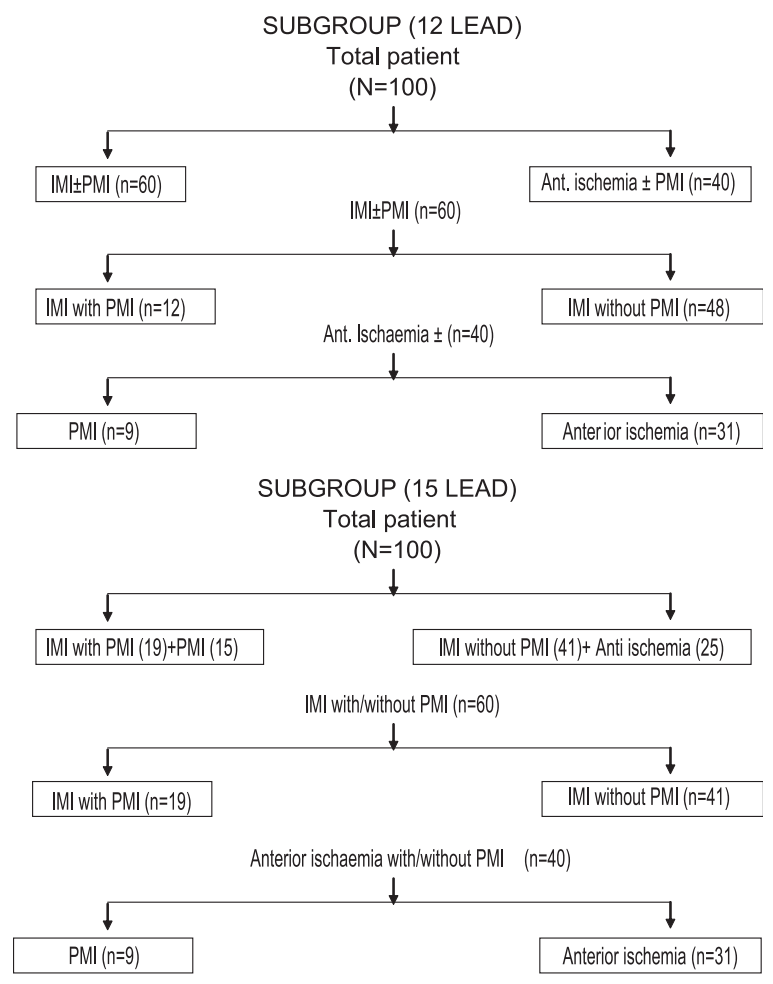

Fig.-1: Flow chat showing patient distribution in two subgroups 
Tale-IV

In hospital complications of the study population

\begin{tabular}{lcccc}
\hline Complication & Group-I(N=34) & Group-II(n=66) & Total(N=100) & P value \\
\hline Recurrent Chest Pain & $1(2.9)$ & $1(1.5)$ & $2(2.0)$ & $0.0629^{\mathrm{NS}}$ \\
Heart Block & 04 & 09 & 13 & $0.0860^{\mathrm{NS}}$ \\
Heart failure & 08 & 07 & 15 & $0.009^{\mathrm{S}}$ \\
Arrhythmia & 07 & 06 & 13 & $0.147^{\mathrm{NS}}$ \\
Mechanical complication & 10 & 06 & 16 & $0.002^{\mathrm{S}}$ \\
(Mitral regurgitation) & & & & \\
Death & 07 & 02 & 09 & $0.004^{\mathrm{S}}$ \\
\hline
\end{tabular}

*p value reached from chi-square analysis; NS $=$ Not significant $(p>0.05)$.

Table-IV Shows the in-hospital complications of Acute Myocardial Infarction in terms of recurrent chest pain, heart failure, arrhythmia, heart block, and death. $23.5 \%$ had heart failure followed by $20.6 \%$ death, $20.5 \%$ arrhythmia, $11.8 \%$ heart block and $2.9 \%$ had recurrent chest pain in group I, whereas $13.6 \%$ heart block followed by heart failure (10.6\%), arrhythmia (9.1\%), death (3.0\%) and $1.5 \%$ had recurrent chest pain in group II.
Significant in-hospital complications were found among the group I in heart failure and death $(p<0.05)$, but no statistically significant difference was found in terms of recurrent chest pain, arrhythmia and heart block between two groups $(p>0.05)$. It was found that $37.0 \%$ had mitral regurgitation among the group-I, whereas it was $9.4 \%$ in group II and the difference was statistically significant $(\mathrm{p}<0.05)$.

Table-V

Wall motion abnormality by Echocardiography among the study population

\begin{tabular}{lcccc}
\hline Wall motion & Group-1 $(\mathrm{n}=27)$ & Group-II $(\mathrm{n}=64)$ & Total $(\mathrm{N}=91)$ & P value \\
\hline Anterior & & & & \\
Normal & $3(11.1)$ & $15(23.4)$ & $18(19.8)$ & $0.134^{\mathrm{NS}}$ \\
Hyperkinesias & $24(88.9)$ & $45(77.3)$ & $69(75.8)$ & \\
Akinesia & $0(0.0)$ & $4(6.2)$ & $4(4.4)$ & \\
Posterior Wall & & & & \\
Normal & $0(0.0)$ & $64(100.0)$ & $64(70.3)$ & \\
Hyperkinesias & $16(59.2)$ & $0(0.0)$ & $16(17.6)$ & \\
Akinesia & $11(40.8)$ & $0(0.0)$ & $11(12.0)$ & \\
Inferior Wall & & & & \\
Normal & $15(51.8)$ & $25(39.1)$ & $40(43.9)$ & \\
Hyperkinesias & $11(40.7)$ & $34(53.1)$ & $45(49.4)$ & \\
Akinesia & $1(3.7)$ & $5(7.8)$ & $6(6.6)$ & \\
Lateral Wall & & & & \\
Normal & $26(96.3)$ & $62(96.8)$ & $88(96.7)$ & $3(3.3)$ \\
Hyperkinesias & $1(3.7)$ & $2(3.2)$ & $1(1.1)$ & \\
Akinesia & $0(0.0)$ & $1(1.6)$ & & \\
Septal Wall & & & $90(98.9)$ & \\
Normal & $27(100.0)$ & $63(98.4)$ & $1.00^{\mathrm{NS}}$ \\
Hyperkinesias & $0(0.0)$ & $1(1.6)$ & $81(89.9)$ & $1.00^{\mathrm{NS}}$ \\
Apical Wall & $25(92.6)$ & $56(87.5)$ & $10(11.0)$ & \\
Normal & $2(7.4)$ & $8(12.5)$ &
\end{tabular}

$\mathrm{P}$ value reached from chi-square analysis/Fisher's exact test 
Table VI

Echocardiographic mean percent of ejection fraction

\begin{tabular}{llclc}
\hline Patients & $\mathrm{N}$ & Mean & SD & P value \\
\hline Group-I & 27 & 49.5 & 6.4 & $0.001 \mathrm{~S}$ \\
Group-II & 64 & 54.5 & 5.9 & \\
Total & 91 & 52.8 & 6.5 & \\
\hline
\end{tabular}

$\mathrm{P}$ value reached from unpaired student's test

$\mathrm{S}=$ Significant $(\mathrm{p}<0.05)$

Table-VII

Coronary Angiography results of the study population

\begin{tabular}{lcccc}
\hline CAG/vessel & Group-I(n=18) & Group-II $(\mathrm{n}=42)$ & Total(N=60) & p value \\
\hline Single vessel & $6(33.3)$ & $15(35.7)$ & $21(35.0)$ & $0.982 \mathrm{NS}$ \\
LAD & - & $6(14.3)$ & $6(10.0)$ & \\
RCA & $1(5.5)$ & $7(16.7)$ & $8(13.3)$ & \\
LCX & $5(27.8)$ & $2(4.8)$ & $7(16.7)$ & \\
Double vessel & $9(50.0)$ & $20(47.6)$ & $29(48.3)$ & \\
LAD+LCX & $4(22.2)$ & $5(11.9)$ & $9(15.0)$ & \\
LAD+RCA & - & $9(21.4)$ & $9(15.0)$ & \\
RCA+LCX & $5(27.8)$ & $6(14.3)$ & $11(18.3)$ & \\
Triple vessel & $3(16.7)$ & $7(16.7)$ & $10(16.7)$ & \\
\hline
\end{tabular}

$\mathrm{P}$ value reached from chi-square analysis

$\mathrm{NS}=$ Not significant $(\mathrm{p}>0.05)$

Table-VIII

Lesion in of LCX among the study population

\begin{tabular}{lcccc}
\hline Vessel & Group-I(n=18) & Group-II(n=42) & Total(N=100) & P value \\
\hline LCX with or without other vessel & $17(94.4)$ & $20(47.6)$ & $37(61.7)$ & $0.001 \mathrm{~S}$ \\
Without LCX & $1(5.6)$ & $22(52.4)$ & $23(38.3)$ & \\
\hline
\end{tabular}

$\mathrm{P}$ value reached from chi-square analysis

Table IX

Dominant vessel in CAG among the study population

\begin{tabular}{lcccc}
\hline Dominant vessel & Group-I(n=18) & Group-II(n=42) & Total(N=60) & P value \\
\hline Right dominant & $9(50.0)$ & $37(88.1)$ & $46(76.7)$ & $0.001 \mathrm{~S}$ \\
Left dominant & $9(50.0)$ & $4(11.9)$ & $13(23.3)$ & \\
\hline
\end{tabular}

$\mathrm{P}$ value reached from chi-square analysis

$\mathrm{S}=$ Significant $(\mathrm{p}<0.05)$

Table X

Wall motion abnormalities by LV graphy among the study population

\begin{tabular}{lcccc}
\hline WMA by LV graphy & Group-I(n=18) & Group-II(n=42) & Total(N=60) & P value \\
\hline Anterolateral & $2(11.1)$ & $4(9.5)$ & $6(10.0)$ & $0.001 \mathrm{~S}$ \\
Anterobasal & $0(0.0)$ & $5(11.9)$ & $5(8.3)$ & \\
Apical & $0(0.0)$ & $5(11.9)$ & $5(8.3)$ & \\
Poster basal & $6(33.3)$ & $3(7.1)$ & $9(15.0)$ & \\
Inferior & $0(0.0)$ & $22(52.4)$ & $22(36.7)$ & \\
Poster lateral & $10(55.6)$ & $3(7.1)$ & $13(21.7)$ & \\
Septal & $0(0.0)$ & $0(0.0)$ & $0(0.0)$ & \\
\hline
\end{tabular}

$\mathrm{S}=$ Significant $(\mathrm{p}<0.05)$ 
Table XI

Sensitivity and specificity analysis of diagnostic evaluation of 12-Lead and 15-Lead ECG compared with Echocardiography.

\begin{tabular}{lccccccc}
\hline Test & \multicolumn{3}{c}{ 12 Lead } & & \multicolumn{3}{c}{ 15 Lead } \\
\cline { 2 - 4 } & Positive & Negative & Total & & Positive & Negative & Total \\
\hline Positive & $13(43.3)$ & $3(4.9)$ & $16(17.6)$ & & $24(80.0)$ & $3(4.9)$ & $27(29.7)$ \\
Negative & $17(56.7)$ & $58(95.1)$ & $75(82.4)$ & & $6(20.0)$ & $58(95.1)$ & $64(70.3)$ \\
Total & $30(100.0)$ & $61(100.0)$ & $91(100.0)$ & & $30(100.0)$ & $61(100.0)$ & $91(100)$. \\
Sensitivity & $43.3 \%$ & & $80.0 \%$ & & & \\
Specificity & $95.1 \%$ & & & & $95.1 \%$ & & \\
\hline
\end{tabular}

Table XII

Sensitivity and specificity analysis of diagnostic evaluation of 12-lead, 15-lead and Echocardiography compared with Ventriculography

\begin{tabular}{|c|c|c|c|c|c|c|c|c|c|}
\hline \multirow[t]{2}{*}{ Test } & \multicolumn{3}{|c|}{12 Lead } & \multicolumn{3}{|c|}{15 Lead } & \multicolumn{3}{|c|}{ Echocardiography } \\
\hline & $+\mathrm{ve}$ & -ve & Total & $+\mathrm{ve}$ & $-\mathrm{ve}$ & Total & $+\mathrm{ve}$ & -ve & Total \\
\hline Positive & $7(35.0)$ & $4(10.0)$ & $11(18.3)$ & $15(75.0)$ & $3(7.5)$ & 18(30.0) & $18(90.0)$ & $2(5.0)$ & $20(33.3)$ \\
\hline Negative & $13(65.0)$ & $36(90.0)$ & $49(81.7)$ & $5(25.0)$ & $37(92.5)$ & $42(70.0)$ & $2(10.0)$ & $38(95.0)$ & $40(66.7)$ \\
\hline Total & $20(100.0)$ & $40(100.0)$ & $60(100.0)$ & $20(100.0)$ & $40(100.0)$ & $60(100.0)$ & $20(100.0)$ & $40(100.0)$ & $60(100.0)$ \\
\hline $\mathrm{P}$ value & $001 \mathrm{~S}$ & & $0.001 \mathrm{~S}$ & & $0.001 \mathrm{~S}$ & & & & \\
\hline Sensitivity & $35.0 \%$ & & $75.0 \%$ & & $90.0 \%$ & & & & \\
\hline Specificity & $90.0 \%$ & & & $92.5 \%$ & & & $95.0 \%$ & & \\
\hline
\end{tabular}

Table-V shows the wall motion abnormality detected by echocardiography. It was evident that no statistically significant difference in wall motion was found in group I and group II except posterior wall $(\mathrm{p}<0.05)$

Table-VI shows the echocardiographic mean percent of ejection fraction of the study patients. The mean percent of ejection fraction was $49.5 \pm 5.9$ in group II. It was found that the mean percent of ejection fraction was significantly lower in groupI than group-II $(\mathrm{p}<0.05)$.

It was observed that about one third (35.0\%) had single coronary artery involvement in CAG finding, 48.3\% had double blood vessel lesion and only $16.7 \%$ had triple vessel lesion. No statistically significant difference was found between group I and group II ( $p>0.05)$. (Table VII)

Table X shows the ventriculographic findings of the study patients. It was found that $88.9 \%$ had poster basal and poster lateral lesion whereas $14.2 \%$ had posterior lesion in group II group and $76.2 \%$ had other site lesion. A statistically significant difference was found between group I and group II in ventriculographic findings indicating group I had posterior myocardial infarction $(\mathrm{p}<0.05)$.

Table XI shows the sensitivity and specificity analysis of 12 and 15 lead compared with echocardiography. Regarding diagnosis of posterior myocardial infarction, $43.3 \%$ sensitivity and $95.1 \%$ specificity was found in 12 lead, whereas in 15 lead it was $80.0 \%$ sensitivity and $95.1 \%$ specificity.

Table XII shows the sensitivity and specificity analysis of 12, 15 lead and echocardiography compared with ventriculography. The sensitivity were $35.5 \%$, $75.0 \%$ and $90.0 \%$ in 12 lead, 15 lead and echocardiography and specificity was $90.0 \%, 92.5 \%$ and $95.0 \%$ in 12 lead, 15 lead and echocardiography.

\section{Discussion:}

Diagnosis of acute posterior myocardial infarction is often missed on routine 12 lead ECGs . Boden et al ${ }^{13}$ suggested that pericardial ST segment depression with an upright $\mathrm{T}$ wave is an early 
electrocardiographic sign suggestive of posterior myocardial infarction .

Agarwal et al. ${ }^{14}$ found that PMI often have anterior ST segment depression and are considered to have unstable angina with ischemia in the anterior descending coronary artery distribution or even left main coronary related infarction. Recording of posterior chest leads (V7-V9) particularly in patients with anterior ST segment depression is an easy method to diagnose posterior infarction. This may help the clinicians in managing the patients. Shah and Berman ${ }^{15}$ demonstrate that patients with a first inferior myocardial infarction who had concomitant pericardial ST depression had more frequent and severe reduction of LVEF than do those without precordial ST segment depression. Patients with such ST depression had higher peak serum CK-MB level and more frequent in-hospital complications than did patients without such ST depression. Pericardial ST segment depression in a setting of first acute infarction involving the inferior wall represent more extensive ischemic injury to the left ventricle most, likely due to posterior myocardial infarction.

About 43 percent patients with pericardial ST segment depression did have anterolateral wall motion abnormalities, but these occurred only in patients with very extensive poster lateral wall motion abnormalities. Prognostic significance of pericardial ST segment depression was studied by various authors. Krone et al. ${ }^{16}$ conducted studies to determine whether pericardial ST segment depression had any prognostic significance. They indicated that pericardial ST segment depression in acute inferior myocardial infarction predicted poor short term and long-term prognosis and had a hospital mortality rate of $13 \%$ compared with 4 percent in patients without ST depression. Most of the patients with anterior ischemia as evidenced by 12 lead ECGs were the mirror image of posterior myocardial infarction evidence by 15 lead ECGs.

The mean $( \pm \mathrm{SD})$ age of this study population was $51.9 \pm 9.0$ years. The majority of the patients $(44 \$)$ were in the age group 40-50 years. Similar findings wes Gibson et al. ${ }^{17}$ who showed mean age as 52 years. In the Bangladeshi population, Rahim 18 reported a mean age of 51 years (range 23-75 years) among the patients with myocardial infarction. When the mean age was compared between two groups i.e. in group I and group II, showed no statistically significant difference $(p>0.5)$. In the present study, there were $13 \%$ female.

Among the risk factors, Cigarette smoking was the commonest, $55 \%$ seen in the study patients, $32 \%$ had history of hypertension and $19 \%$ had diabetic. On comparison of the risk factors (including lipid profile) in the two groups, no statistically significant difference was found ( $p>0.05)$.

Cardiac enzyme (CK-MB) was elevated both on admission and six hours after admission in group I and the enzyme level between two groups was statistically significant $(p<0.001)$. This finding was comparable to the findings of Gellman and Saltrups 19 that showed that peak. CK-MB level of patients with pericardial ST segment depression (1779 U/ $\mathrm{L})$ was statistically higher $(\mathrm{p}<0.001)$ than without ST depression (1090 U/L). The higher level of peak CK levels to the larger infarcts seen in the patients with pericardial ST segment depression. Matetzky S et al. ${ }^{7}$ showed in PMI, Creatine Kinase (CK) was elevated twice the upper normal limit. The mean CK-value was $663 \pm 314$ IU/L. The upper normal range was $90 \mathrm{IU} /$ litre).

In this study, cent percent of the study population presented with the complains of chest pain. One fifth of cases (19.0\%) complaints of back pain in association with retrosternal pain. This presentation (back pain) was statistically significant $(\mathrm{p}<0.001)$. Menown A B et $\mathrm{al}^{20}$ mentioned that posterior wall involvement may present with pain radiating to the back. But they did not mention how many percent patients with posterior well infarction were suffered.

In this study, highest percentage were inferior myocardial infarction with anterior ischaemia 33.0 $\%$ followed by anterior ischemia $31.0 \%$ inferior myocardial infarction (MI) with posterior myocardial infarction (PMI) with anterior ischemia $10 \%$, IMI and PMI $2 \%$ and IMI $15 \%$ were detected by using 12 lead ECGs.

Similarly in 15 lead ECGs- similar pattern of ECG findings were found, where $26 \%$ was IMI with anterior Ischemia, followed by anterior Ischemia $25 \%$ IMI and PMI with anterior Ischemia 16\%, PMI with anterior ischemia $3 \%$ and PMI with IMI $3 \%$ were detected. 
Cases $\mathrm{RE}$ et al. ${ }^{21}$ in their study, by using additional three leads (V7-V9) of patients with either because of tall $\mathrm{R}$ waves in V1 and/or V21 or because of clinical suspicion of posterior infarction had shown that out of 250 patients 110 patients (44\%) showed evidence of new or old posterior myocardial infarction consisting of ST segment elevation and / or board Q waves in elad V7, V8, V9 in 27 them (10.8\%) only these were diagnostic of infarction. In 83 others (33.2\%) signs of infarct also were present in inferior (LII LIII aVF) or occasionally in high lateral leads as well. Gibson RS et al. showed only 5 percent posterior myocardial infarction was associated with IMI without ST segment depression and 26 percent PMI associated with IMI with anterior Ischemia patients. ${ }^{17}$

Matetzky S et al. ${ }^{22}$ demonstrated that 53 percent had significant ST segment elevation in posterior chest leads V7-V9 of patients with inferior myocardial infarction. Matetzky S et al. ${ }^{7}$ showed, ST segment elevation was present as many as $20 \%$ of AMI patients without ST elevation on the standard 12 lead ECGs. Boden WE et al. ${ }^{10}$ showed that non Q-wave anterior AMI patients progressed to posterior AMI (approximately 30\% of all Q wave infarction).

The ECGs findings of the present study was comparable with the above studies abroad in this study, 31.3\% IMI patients were associated with $\mathrm{PMI}$ and $37.5 \%$ anterior ischemia associated with PMI. Sensitivity and specificity for diagnosis of acute PMI by conventional 12 lead as compared with 2D Echocardiography and LV graphy which was $43.3 \%$ sensitivity and $95.1 \%$ specificity compared with echocardiography whereas it was $35.0 \%$ sensitivity and $90.0 \%$ specificity compared with LV graphy. On the contrary, in 15 lead, 80.0\% sensitivity and $95.1 \%$ specificity compared with echocardiography, this was $75.0 \%$ specificity compared with echocardiography, this was $75.0 \%$ sensitivity and $92.5 \% \%$ specificity compared with LV graphy. So, compared with conventional 12 leads, 15 lead could be more sensitive and specific $(p<0.05)$ tool for the diagnosis of PMI. Matetzky et al ${ }^{7}$ showed the sensitivity was $44 \%$ and specificity was $97 \%$ in 12 lead ECG, whereas 91\% sensitivity and $97 \%$ specificity in 15 lead ECG compared with echocardiography. On follow up a total $36 \%$ patients were presented with complains of shortness of breath. Among them $19 \%$ from case group and the difference between the groups in the presentation of shortness of breath was statistically significant $(p<0.003)$. The clinical evidence of heart failure was graded using Killips classification. 33.5 $\%$ patients from group I and 10.6 percent from group I had clinical evidence of heart failure. Patients in group I more often had heart failure class III and IV than in group II ( $14.7 \%$ vs. $3 \%)$. This difference was statistically significant $(p<0.001)$. Matetzky $\mathrm{S}$ et al. ${ }^{22}$ compared heart failure in the patients with or without ST segment elevating in the posterior chest leads. They showed that patients having St segment elevation more often had heart failure (11\% vs. $5 \%)$ than patients without St segment elevation.

Arrhythmia (13\%) and conduction disturbances (13 $\%)$ were seen in the study patients. $20.5 \%$ of the patient in group I had arrhythmias, premature ventricular contraction being the most common (11.8\%). Conduction disturbances were seen in 11.7 $\%$ in group I and $10.3 \%$ in group II. There were no statistically significant difference was found between two the groups ( $>00.05)$. Death rate was higher in group I (20.6 \%) than group II (3\%). This was statistically highly significant $(p<0.001)$. The mortality rate was a bit higher than other study showed by Matetzky S et al ${ }^{22}$ where the rate 6.5 $\%$. This difference may be due to small sample size.

Echocardiographic evaluation of wall motion abnormalities showed that posterior wall was hyperkinetic as well as akinetic in patients in group I. Inferior wall hyperkinesias was in $40.7 \%$ and akinesia $3.7 \%$, lateral wall was $3.7 \%$ hyperkinesias in group I of patients. It was evident that no statistically significant wall motion difference was found in between two groups except posterior wall, had significant wall motion abnormality $(\mathrm{p}<0.05)$, Matetzky S et al ${ }^{7}$ had performed echocardiographic study in the patients with posterior myocardial infarction and showed that left ventricular posterior wall motion abnormality was the most common regional dysfunction, which was evidenced in 97 $\%$ patients. Inferior and lateral wall motion abnormalities were found in $47 \%$ and $41 \%$ respectively. The posterior wall was also the most severely abnormal being akinetic or dyskinetic in 
$61 \%$. Ejection fraction by echocardiography showed the moderate to severe LV dysfunction in group-I and mild to moderate in-group-II. Matetzky S et al. ${ }^{7}$ found similar result by echocardiography. 89 Among the mechanical complications the incidence of mitral regurgitation was more $38.9 \%$ in the patients of group I and only $11.9 \%$ in group II by LV graphy. This was statistically highly significant $(p<0.001)$. Matetzky S et al. ${ }^{7}$ was detected moderate to severe MR in $22 \%$ patient and mild MR in an additional $47 \%$ patients having posterior myocardial infarction.

Total 60 of the patients underwent coronary angiography. Among them 18 patients from group I and 42 patients from group-II. In group-I single vessel involvement LCX (5(27.8\%), RCA 1(-5.5\%), double vessel involve RCA+LCX 5(27.8\%), LAD+LCX 4(22.2\%). Triple vessel involved only $3(16.7 \%)$.

Among the total 18 patients, LCX involvement was in 17 patients (94.4\%), Among the patients from group II, single vessel involvement was 15 (35.7\%), double vessels 20(47.6\%) and triple vessels 7(16.7\%). Among the total 42 patients from group II, LCX involvement was 20(47.6\%). Significant difference was found for involvement of LCX between the two groups. It was comparable with the study by Matetzky S et al ${ }^{7}$ where it was shown that $80 \%$ patients had mid-portion LCX lesion and $20 \%$ patients had lesion in the first marginal branch of the circumflex coronary artery. Casas RE et al ${ }^{21}$ had shown that LCX involvement was more in patients with inferior myocardial infarction associated with posterior myocardial infarction (out of 21 patients LCX involvement in 17 patients) than in patients without involvement of PMI (out at 23 patients - LCX involvement in II patients). It was statistically significant $(\mathrm{p}<0.05)$.

The ejection fraction, wall motion abnormality and mechanical complications were studied during left ventriculography at RAO and LAO projection. The mean $( \pm \mathrm{SD})$ percent of ejection fraction of the group I was $47.3 \pm 4.2$ and group II 53.9 \pm 5 .3. The difference between the groups was statistically highly significant $(p<0.001)$. The findings of this study corroborate with that found by Matetzky S et al. ${ }^{7}$ and this showed that LVEF was lower among the patients with posterior myocardial infarction $(44 \pm 5 \%)$. The wall motion abnormalities on the ventriculography showed the patients in group I had hypokinesia of poster basal and posterior wall motion abnormality in group II. Mitral regurgitation as evidenced by passes of dy from LV to LA during systole during the procedure was detected 38.9\% group I and only $11.9 \%$ in group II. It was comparable with the study Matetzky et al. ${ }^{7}$ who showed that moderate to serve MR was detected 22 $\%$ in patients with posterior myocardial infarction.

\section{Conclusion:}

15 Lead ECGs (including V7-V9) more sensitive than 12 lead ECGs in diagnosis of acute posterior myocardial infarction. Patient with inferior myocardial infarction or anterior ischemia developed more complications if associated with acute posterior myocardial infarction. 15 lead ECGs can routinely be used in patients with ischaemic type of chest pain.

A significant number of anterior ischemia patients actually mirror image of acute posterior myocardial infarction as evidenced by ST segment elevation in V7-V9 in 15 lead ECGs. The identification of latter ECG pattern will enable this sub group of AMI patients to benefit from early thrombolysis or direct PTCA rather than conventional treatment of ischemia.

15 lead ECGs can be helpful in the early diagnosis of acute posterior myocardial infarction in patients with ischemic type of chest pain without change in ST segment in 12 Lead ECGs and thereby facilitation prompt and accurate treatment.

\section{Limitation of the study}

The study was limited by small sample size. Yet, this study is the first attempt to emphasize on proper and prompt diagnosis of acute posterior myocardial infarction by simple 15 lead ECGs, and early detection of complications following acute posterior myocardial infarction, which may reduce the short and long term morbidly and mortality. Thus this study may serve as an impetus for future studies on acute posterior myocardial infarction on a larger scale in our country.

\section{References:}

1. Julian DG. Cowan JC. Diseases of the coronary arteries5th edition. 1988 ELBS publication; 135.

2. Malik A. Congenital and Acquired Heart disease. A suvery of 7062 persons. MBRC Bulletin. 1976. 2:115-119. 
3. Farid N, Amanullah M, Rahman F. Cardiovasculkar dusease profile in mymensingh zone. An epidemiological over view. Bangladesh Heart J 1993; 8 : 1-7

4. ACC/AHA guidelines for diagnosis and management of Acute Myocardial Infarction 1996.

5. Perlott JK. The recognition of Strictly posterior myocardial Infarction by Conventional scalar Electrocardiography Circulation 1964; Vol XXX, 70618.

6. Berry C, Zalewski A, Kovach R, Savage M, Goldberg S.. Surface electrocardiogram in the Detection of Transmural myocardial Ischemia during Coronary Artery Occlusion. Am J Cardiol 1989 63: 21-26.

7. Matetzky S. Freimark D, Feinberg, Novikov I Rath S. Rabinowitz B et alAcute myocardial Infarction with Isolated ST-segment elevation in posterior chest leads V7-V9. J Am Col Cardiol 1999; 34: 748-53

8. Shlomi M, Dov F, Micha S et Al. Acute myocardial infarction with isolated St- segment elevation in posterior leads $\mathrm{V}_{7}-\mathrm{V}_{9}$. J Am Col Cardiol 1999; 34: 348353.

9. Goldberg H L. Borer J S. Jacobstein JG. Kluger J. Scheidt SS. Alonso DR. Anterior ST segment depression in Acute inferior myocardial infarction, indicator of poster lateral infarction. Am J Cardiol 1981; 48: 100915 .

10. Boden WE. Kleiger RE. Gibson RS. Schwartz DJ. Schechtman KB. Capone RJ et al. Electrocardiographic Evolution of posterior Acute myocardial infarction; Importance of Early Pericardial ST segment depression. Am J Cardiol 1987; 59; 782-787.

11. Roubin S. Shen WF. Nicholson M. Dunn F. Kelly DT. Harris PJ.. Anterolateral ST segment depression in acute inferior myocardial infarction. Angiographic and clinical implications. Am Heart J 1984; 107: 117-82.

12. Bush ES, Ferguson JJ, Angelini P, Willerson T, Twelvelead electrocardiographic evaluation of Ischemia during percutaheous trausluminal coronary angioplasty and its correlation with acute reclusion. Am Heart J 1991; 121: 1591-99

13. Boden WE. Kleiger RE. Gibson RS. Schwartz DJ. Schechtman KB. Capone RJ et al. Electrocardiographic
Evolution of posterior Acute myocardial infarction; Importance of Early Pericardial ST segment depression. Am J Cardiol 1987; 59: 782-787.

14. Agarwal JB. Khaw K. Aurignac F. Locurto A.. Importance of posterior chest leads in patients with suspected myocardial infarction. But non-diagnostic, Routine 12 lead Electrocardiogram. Am J Cardiol 1999; 83; 323-326.

15. Shah PK, Berman DS. Implications of precordial ST segment depression in Acute inferior myocardial infarction. The Amercian Journal of Cardiology 1981; 48: $1167-1168$.

16. Krone RJ, Greenberg H, Dwyer KM Jr, Kleiger RE, Boden WE, multicenter Diltiazem post infarction Trial Research group. Long term prognostic significance of ST segment depression during acute myocardial infarction. J Am Coll Cardiol 1993; 22: 361-7.

17. Gibson RS. Crampton RS. Watson DD. Taylor GJ. Carabello BA. Holt ND, et al. A precordial ST Segment Depression during acute inferior myocardial infarction; clinical, Scintigraphic and Angiographic correlations. Circulation 1982; 66(4): 732-41.

18. Rahim M. Clinical presentation of acute myocardial infarction, Typical-atypical, Theis, MD (Cardiology). 1993. University of Dhaka. Dhaka.

19. Gelman JS. Saltups A.. Pericardial ST segment depression in patients with inferior myocardial infection: Clinical implications. Br. Heart J 1982; 48: 560-5.

20. Menown A B. Allen J. Andersun JM. Adgey A.A.JEarly diagnosis of Right Ventricular or posterior infarction Associated with inferior wall left ventricular Acute myocardial infarction. Am J Cardiol 2000; 85: 934-38.

21. Casea RE. Marriott HJ. L, Glancy L. Value of leads V7V9 in Diagnosis posterior wall acute myocardial infarction and other causes of Tall $R$ waves in V1-V2. Excerptamedica Inc. 1997. 508-9.

22. Metetzky S. Ferimark D. Chouraqui P. Rabinowitz B, Rath S. Kaplinsky E. et alSignificance of ST segment elevations in posterior chest leads (V7-V9) in patients with Acute inferior myocardial infarction; Application for Thrombolytic Therapy. J Am Coll Cardiol 1998; 31: 506-11 